\title{
Exclusive breast-feeding is rarely practised in rural and urban Morogoro, Tanzania
}

\author{
Restituta Shirima ${ }^{1}$, Ted Greiner ${ }^{2}$, Elisabeth Kylberg ${ }^{2}$ and Mehari Gebre-Medhin ${ }^{2, *}$ \\ ${ }^{1}$ Tanzania Food and Nutrition Centre, Dar es Salaam, Tanzania: ${ }^{2}$ Section for International Maternal and Children's \\ Health, University Hospital, SE-751 85 Uppsala, Sweden
}

Submitted 19 October 1999: Accepted 6 June 2000

\begin{abstract}
Objective: To investigate and compare feeding practices among infants of less than 7 months of age in a rural and an urban area in Tanzania.

Design: Cross-sectional, questionnaire-based interview of mothers and focus group discussions with extension workers and community leaders.

Setting: Eleven villages in a rural district and 10 wards in an urban district in the Morogoro region, Tanzania, west of Dar es Salaam.

Subjects: Probability samples of mothers with infants of less than 7 months of age $(n=320$ from each area).

Results: Exclusive breast-feeding was rarely practised in either the rural or urban areas investigated. However, the urban mothers initiated breast-feeding earlier, discarded colostrum less frequently, breast-fed exclusively for a longer period, gave breast milk as the first feed more often and delayed the introduction of solid foods for longer than their rural counterparts. The rural mothers, on the other hand, breastfed their previous infants slightly longer than the urban mothers.

Conclusions: The better performance of urban mothers could be partly due to sustained breast-feeding support in hospital settings and other campaigns which may not have reached the rural areas. In both the rural and urban areas more efforts are needed to encourage exclusive breast-feeding, to avoid premature complementation and, in the case of the urban areas, to protect extended breast-feeding.
\end{abstract}

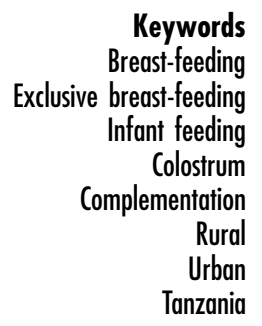

Breast-feeding practices and patterns vary across populations and between individual mothers, depending on a number of factors. In most low income countries initiation of breast-feeding is almost universal ${ }^{1-3}$. The median duration of breast-feeding in 25 countries in Africa that have national data is estimated to be 21 months; and $80 \%$ of infants are breast-fed for over 1 year ${ }^{2}$. Although wide variations exist, exclusive breast-feeding is rare in most of these countries. According to a World Health Organization (WHO) estimate the proportion of infants under 4 months currently receiving breast milk exclusively probably does not exceed $20 \%$ in most African countries ${ }^{2}$. However, current status assessment does not guarantee that infants who were receiving their mother's milk the day before the interview have not received other foods at various times since birth ${ }^{4}$.

Notwithstanding the problem in defining what actually constitutes exclusive breast-feeding, a number of studies have been carried out worldwide focusing on breastfeeding patterns in rural and urban communities. Basically the studies have been of two categories. Firstly, there are those studies which have focused on both rural and urban areas simultaneously, using identical methodology. These studies have consistently shown that although the duration of breast-feeding is longer in rural than in urban areas, exclusive breast-feeding is rare in both areas $^{5-13}$. In Uganda and Madagascar the median duration of exclusive breast-feeding was longer in the rural areas ${ }^{14,15}$; in Eritrea it was longer in the urban areas ${ }^{16}$ while in Mali and Zimbabwe it was the same in both areas $^{17,18}$. Haggerty ${ }^{3}$ has reported that in 19 studied subSaharan African countries, infants living in rural areas are breast-fed on average 3 months longer than their counterparts in urban areas.

Secondly, there have been studies in which either rural or urban areas have been investigated separately. Again a fairly consistent picture has emerged, indicating that a high proportion of mothers breast-feed their children, but exclusive breast-feeding is almost non-existent in both rural and urban areas. Further, these studies have again shown that the duration of breast-feeding is longer in rural areas than in urban areas ${ }^{19-27}$. 
Similarly, the practice of breast-feeding is almost universal in Tanzania ${ }^{12,25,28}$. The Tanzania Demographic and Health Survey (TDHS ${ }^{28}$ reports a median overall breast-feeding duration of 22 months, with little difference between rural and urban areas. The median age of infants currently exclusively breast-fed among those below 4 months of age was 1.3 months in the rural areas, and 0.6 months in the urban ones. These rates must be considered as exceedingly low. Yet, detailed studies on patterns, practices and beliefs related to exclusive breastfeeding for Tanzania are lacking in the published literature. The Baby Friendly Hospital Initiative (BFHI) was initiated in Tanzania in 1992. Nearly a quarter of the maternity hospitals in the country have so far been assessed 'baby friendly'. This means many health workers from the health facilities utilized by urban mothers have had access to current information on recommended infant feeding. However, little is known about the effect of this programme in promoting exclusive breast-feeding, in particular whether mothers continue with optimal breastfeeding once they return to the community after delivery.

The present study investigates early infant feeding in a rural and an urban area simultaneously, using the same methodology. The aim of the study was to obtain data on the patterns of infant feeding, including types of feeds given in the early months of life and also on the mothers' knowledge and practices regarding breast-feeding issues, and the reasons for early supplementation.

\section{Materials and methods}

\section{Study area and study population}

This study is descriptive and cross-sectional in design and was conducted in December 1998 in a rural division and in January 1999 in urban wards in the Morogoro region, Tanzania, situated about $200 \mathrm{~km}$ west of Dar es Salaam. Tanzania's 20 mainland regions are divided into districts, divisions, wards and then villages, which form the lowest level of administration. The total population in the Morogoro region is estimated to be 1.2 million, with $78 \%$ living in rural areas. The population growth rate was estimated at $2.6 \%$ in $1988^{29}$.

The sample size required to estimate the proportion exclusively breast-feeding at $0-5$ months of age was calculated using Statcalc in Epi Info 6. We conducted population surveys in two areas with an estimated population of 44000 in the rural area and 80000 in the urban. The expected frequency was $29 \%{ }^{28}$ and the worst acceptable value chosen was $\pm 5 \%$. Using a confidence level of $95 \%$, the required sample sizes were 314 and 315 , respectively. In each area 320 mothers were chosen in case of refusals. Of the five districts in Morogoro, those named Morogoro Rural and Morogoro Urban were selected as typical urban and rural areas with appropriate population sizes. Fig. 1 illustrates the sampling procedure in the rural and urban areas.
Of the 10 divisions in Morogoro Rural District, one division was randomly chosen for the study. Of its four wards, one was inaccessible; of the 14 villages in the three remaining wards, three villages were also not accessible. Thus a total of 11 rural villages were included in the study.

The Morogoro Urban District is divided into 19 wards, which are further divided into streets. For purposes of comparison, these wards were considered to be equivalent to the villages in the rural area. Ten wards in the Morogoro Urban District were randomly sampled.

Using probability proportional to size (1988 census), the likely number of eligible mothers from each village was established. In each village or ward, all mothers with singleton children of less than 7 months of age were listed with the help of village health workers and community leaders. From the listed mothers, subjects were randomly selected until the quota was filled for each village or ward. Each selected mother was asked verbally for her consent to participate in the study and all of them were willing to do so. Ethical clearance for the study was obtained from the Ethics Committee of the Tanzania Food and Nutrition Centre and the Research Ethics Committee of Uppsala University, Sweden.

\section{Data collection}

\section{Questionnaire-based interviews}

A pretested, structured questionnaire administered in Kiswahili, the national language, was used to obtain the quantitative data. The interview, which lasted for 35$45 \mathrm{~min}$, took place in the mothers' homes. The questionnaire was divided into seven major parts which included: demographic information about the mother and family members, reproductive history of the mother, birth and feeding history, current infant feeding practices, previous breast-feeding experience, source of child feeding information, and maternal knowledge and beliefs about breast-feeding issues.

Anthropometric measurements were carried out on the mothers, using a Secca electronic balance, which was checked daily, and a height-measuring board with a fixed footboard, a fitted measuring tape and a movable headpiece. Height was recorded to the nearest $0.1 \mathrm{~cm}$ and weight to the nearest $0.1 \mathrm{~kg}$. Body mass index (BMI = weight in kilograms/height in metres squared) was used to assess the nutritional status of the mothers.

\section{Focus group discussions}

Focus group discussions were conducted in six villages among groups homogeneous in terms of age, education, socioeconomic status and occupation. Participants in the group discussions were recruited with the assistance of community leaders, and included: respected and influential older women who were considered knowledgeable in the community (grandmothers); traditional birth attendants; community leaders; mothers of child-bearing age 


\section{RURAL}

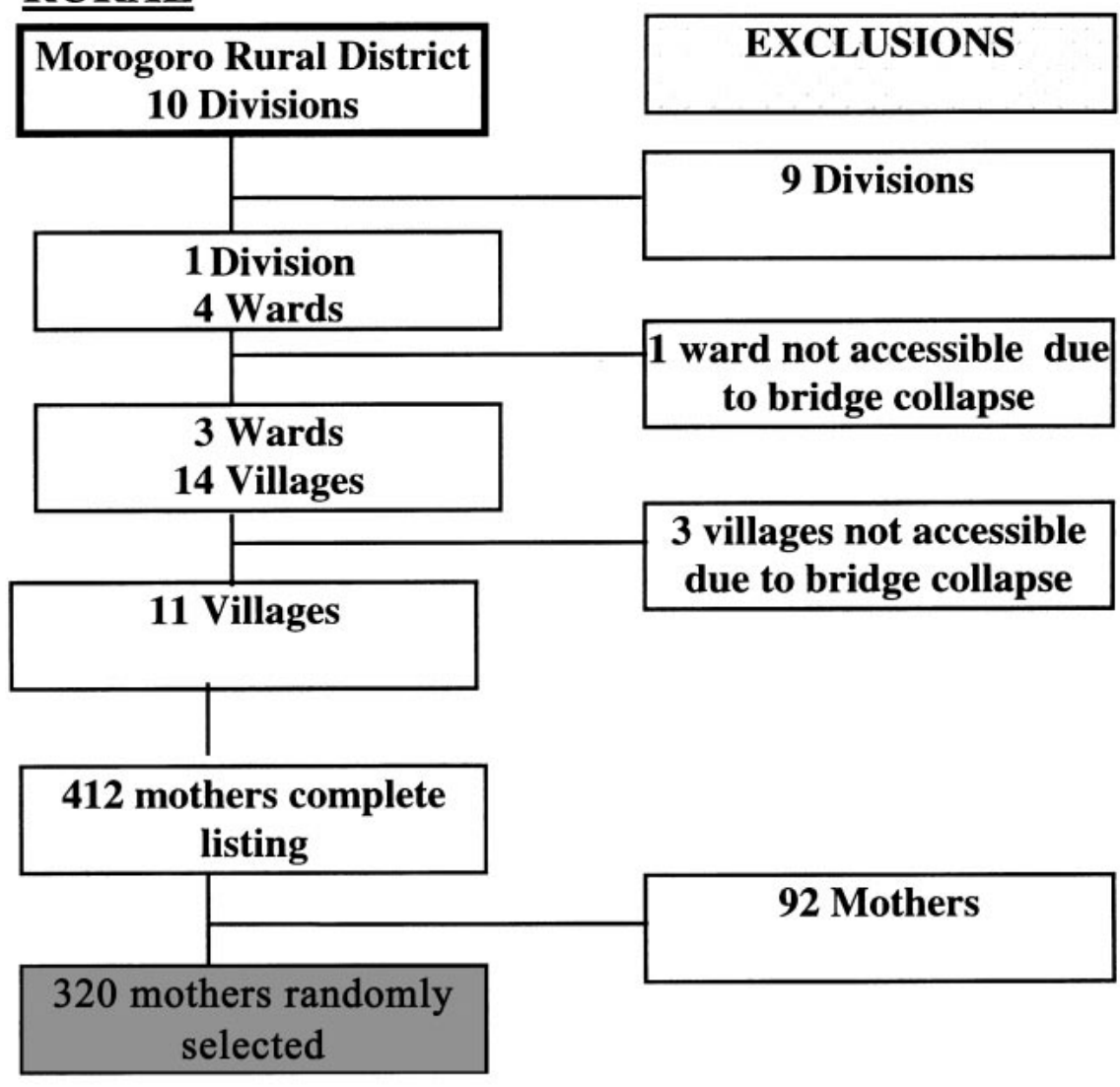

URBAN

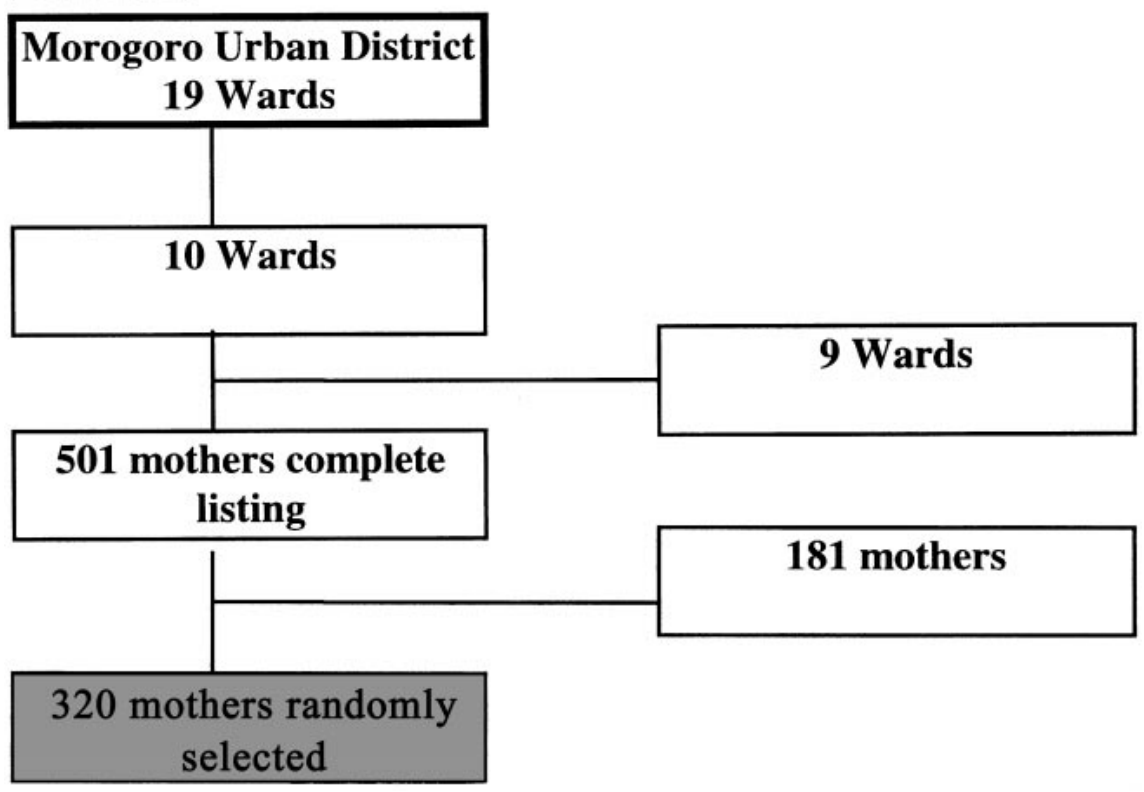

Fig. 1 Illustration of the rural and urban sampling processes in the Morogoro region 
(19-38 years), most with primary education; health workers (trained nurses, assistant medical officers and nurse assistants); and extension workers. The discussions were held in a school building, health centre or village office.

Pretested focus group guidelines were used to elicit perceptions and beliefs about the initiation of breastfeeding, traditional prelacteal feeds, colostrum, exclusive breast-feeding, milk expression, benefits and disadvantages of breast-feeding, beliefs, attitudes and taboos regarding infant feeding, and about problems with breast-feeding and complementation. The information obtained was used to validate the quantitative data obtained from the questionnaire-based interviews, but is not itself analysed and presented here.

\section{Definitions used in the present study}

The following definitions were applied.

- Exclusive breast-feeding: the mother reported that nothing else but breast milk was being given at the time of the interview.

- Initiation of breast-feeding: estimated according to the mother's report of the events that had occurred before breast-feeding commenced.

- Partial discarding of colostrum: some of the colostrum was discarded by expressing it before each breast-feed.

- Predominant breast-feeding: in addition to breast milk, the infant may be receiving water-based drinks; no foodbased fluid or milk was allowed.

- Full breast-feeding: breast-feeding exclusively or predominantly.

- Partial breast-feeding: breast-feeding with supplements of milk or solids (including food-based fluids).

- Any breast-feeding: breast-feeding exclusively, predominantly or with any supplements, including milk and solids.

- Breast-feeding duration: all sample infants were still being breast-fed; hence the duration referred to was for the sibling preceding the index child. Thus the available information is only for multiparas.

\section{Data analysis}

The data processing was carried out with Epi Info 6 and SPSS PC 9.0 statistical software. Data were checked for normality and means; standard deviations and medians were calculated. The $t$-test was used for comparing means, and the chi-square test for comparing categorical variables. Survival analysis was used to estimate the duration of exclusive or predominant breast-feeding based on recall of ages when different supplements were first given. A $P$ value $<0.05$ was used as the criterion for statistical significance.

\section{Results}

Basic information on the study population by residence

Table 1 shows some characteristics of the rural and urban
Table 1 Selected characteristics of the study population in Morogoro (mean with SD, or per cent), by residence

\begin{tabular}{|c|c|c|c|}
\hline Variable & $\begin{array}{c}\text { Rural } \\
(n=320)\end{array}$ & $\begin{array}{c}\text { Urban } \\
(n=320)\end{array}$ & $P$ value \\
\hline \multicolumn{4}{|l|}{ Mother } \\
\hline Age (years) & $26 \pm 6$ & $24 \pm 5.8$ & 0.03 \\
\hline No. of live children & $2.8 \pm 1.7$ & $2.2 \pm 1.6$ & 0.001 \\
\hline Height (cm) & $152 \pm 7.7$ & $155 \pm 5.7$ & 0.001 \\
\hline Weight (kg) & $52 \pm 6.9$ & $56 \pm 10$ & 0.001 \\
\hline BMI & $22 \pm 2.7$ & $23 \pm 3.8$ & 0.001 \\
\hline Education (years) & $4.3 \pm 3.5$ & $6.6 \pm 2.7$ & 0.001 \\
\hline none & 38 & 10 & 0.001 \\
\hline Multiparous & 76 & 59 & 0.001 \\
\hline \multicolumn{4}{|l|}{ Occupation } \\
\hline Housewife/other & 7 & 84 & \\
\hline Farmer & 93 & 16 & 0.001 \\
\hline Delivery at home & 65 & 14 & 0.001 \\
\hline Married & 77 & 80 & 0.3 \\
\hline \multicolumn{4}{|l|}{ Father } \\
\hline Education (years) & $\begin{array}{l}5.7 \pm 3.6 \\
(n=243)\end{array}$ & $\begin{array}{l}8.6 \pm 2.6 \\
(n=249)\end{array}$ & 0.001 \\
\hline Age (years) & $\begin{array}{l}33 \pm 9.7 \\
(n=165)\end{array}$ & $\begin{array}{l}33 \pm 8.4 \\
(n=196)\end{array}$ & 0.6 \\
\hline \multicolumn{4}{|l|}{ Index child } \\
\hline Birth weight (kg) & $\begin{array}{l}3.2 \pm 0.5 \\
(n=119)\end{array}$ & $\begin{array}{l}3.0 \pm 0.5 \\
(n=296)\end{array}$ & 0.0005 \\
\hline Age (months) & $3.6 \pm 1.6$ & $2.8 \pm 1.8$ & 0.001 \\
\hline Sex (girls) & 52 & 53 & 0.7 \\
\hline \multicolumn{4}{|l|}{ Socioeconomic factors } \\
\hline \multicolumn{4}{|l|}{ Type of floor } \\
\hline Mud & 90 & 19 & 0.001 \\
\hline Cement & 9.7 & 81 & \\
\hline \multicolumn{4}{|l|}{ Type of roof } \\
\hline Grass/bamboo & 70 & 5 & \\
\hline Corrugated metal & 30 & 95 & 0.001 \\
\hline \multicolumn{4}{|l|}{ Type of wall } \\
\hline Mud/mud bricks & 91 & 30 & \\
\hline Cement bricks & 9.4 & 70 & 0.001 \\
\hline \multicolumn{4}{|l|}{ Asset ownership } \\
\hline Owns radio & 46 & 72 & 0.001 \\
\hline Owns bicycle & 25 & 37 & 0.001 \\
\hline
\end{tabular}

BMI, body mass index.

mothers. The rural mothers had had fewer years at school, were nearly always farmers, and more often delivered at home. The age distribution of the fathers was similar in the two areas, but the urban fathers had more education than the rural ones. The urban infants were on average younger and had lower birth weight. The housing standard and ownership of radios and bicycles was high in the urban area.

\section{Mothers' knowledge on infant feeding}

The urban mothers were nearly always more knowledgeable in respect to early infant feeding issues than the rural ones (Table 2). In breast-feeding management, most mothers in both areas were unaware of key issues. Advantages of breast-feeding mentioned by all mothers were related only to the baby. 
Table 2 Mothers' knowledge and opinions on infant feeding issues, by residence $(n=320)$

\begin{tabular}{|c|c|c|c|c|c|c|}
\hline \multirow[b]{2}{*}{ Question } & \multirow[b]{2}{*}{ Mother's response } & \multicolumn{2}{|c|}{ Rural } & \multicolumn{2}{|c|}{ Urban } & \multirow[b]{2}{*}{$P$} \\
\hline & & $n$ & $\%$ & $n$ & $\%$ & \\
\hline Appropriate time to & Within 1 hour & 190 & 59 & 254 & 79 & \\
\hline initiate breast-feeding & $>1$ hour/DK & 130 & 41 & 66 & 21 & 0.001 \\
\hline \multirow{2}{*}{$\begin{array}{l}\text { What is the importance } \\
\text { of colostrum? }\end{array}$} & Nutritious/protective/both & 79 & 25 & 141 & 44 & \multirow[b]{2}{*}{0.001} \\
\hline & No importance/bad/DK & 241 & 75 & 179 & 56 & \\
\hline For how long is breast & $\leq 3$ months & 247 & 77 & 216 & 68 & \\
\hline $\begin{array}{l}\text { milk alone sufficient } \\
\text { for an infant? }\end{array}$ & $\geq 4$ months & 73 & 23 & 104 & 33 & 0.01 \\
\hline \multirow{2}{*}{$\begin{array}{l}\text { Main cause of } \\
\text { cracked/sore nipples? }\end{array}$} & Baby takes breast wrongly & 7 & 2 & 16 & 5 & \multirow[b]{2}{*}{0.09} \\
\hline & Disease/DK & 313 & 98 & 304 & 95 & \\
\hline \multirow{2}{*}{$\begin{array}{l}\text { How would one know } \\
\text { a baby is getting enough } \\
\text { breast milk? }\end{array}$} & Weight gain/good health & 82 & 25 & 71 & 22 & \multirow[b]{2}{*}{0.4} \\
\hline & Not crying & 238 & 75 & 249 & 78 & \\
\hline What would you do if a & Give formula/cow's milk/porridge/stop BF & 13 & 98 & 303 & 95 & \\
\hline baby is $<4$ months and & Increase BF frequency & 7 & 2 & 17 & 5 & 0.06 \\
\hline $\begin{array}{l}\text { you feel he is not getting } \\
\text { enough breast milk? }\end{array}$ & & & & & & \\
\hline \multirow{2}{*}{$\begin{array}{l}\text { What is the appropriate time } \\
\text { to commence complementation? }\end{array}$} & 1-3 months & 216 & 68 & 179 & 56 & \multirow[b]{2}{*}{0.002} \\
\hline & 4-7 months & 104 & 32 & 141 & 44 & \\
\hline \multirow{2}{*}{$\begin{array}{l}\text { What is the appropriate time } \\
\text { to stop breast-feeding? }\end{array}$} & $1-1.5$ years & 4 & 1 & 13 & 4 & \multirow[b]{2}{*}{0.05} \\
\hline & $2-4$ years & 316 & 99 & 307 & 96 & \\
\hline
\end{tabular}

$\mathrm{BF}$, breast-feeding; DK, do not know.

\section{Breast-feeding management}

Seventeen per cent of the mothers from both areas had experienced cracked or sore nipples; $84 \%$ of all mothers did not know the main cause of this complaint. Only $2 \%$ of the rural and $5 \%$ of the urban mothers stated that in the event of perceived breast milk insufficiency they would breast-feed more frequently. Most of the mothers did not know how to express breast milk, and only 13\% were able to demonstrate this correctly. The main reason for adding complementary foods was infant crying, which mothers perceived to mean that they did not have enough milk. Thin porridge was the most common food given to infants in both areas.

Information and decision making on infant feeding Health personnel (doctor/nurse) and the maternal mother were the main sources of the mothers' information on

Table 3 Source of information on infant feeding issues, by residence

\begin{tabular}{lrrrrr}
\hline & \multicolumn{2}{c}{ Rural } & & \multicolumn{2}{c}{ Urban } \\
\cline { 2 - 3 } \cline { 5 - 6 } Source/person & \multicolumn{1}{c}{$n$} & & & $n$ & $\%$ \\
\hline Doctor/nurse & 165 & 51.1 & & 226 & 70.6 \\
Radio & 18 & 5.6 & & 34 & 10.6 \\
Mother's mother & 99 & 30.9 & & 89 & 27.8 \\
Village health workers & 85 & 26.6 & & 10 & 3.1 \\
Others & 15 & 4.7 & & 19 & 6.0 \\
\hline
\end{tabular}

Multiple answers possible. infant feeding in both areas (Table 3). In the rural area, village health workers were the third most important source of information, while in the urban area this was the radio.

In addition more than half of the mothers in each area reported that they made their own decisions about how to feed the baby, while about 30\% said that their own mother and the child's father (10\%) had an influence on how the baby was fed.

\section{Infant feeding practices}

Exclusive breast-feeding was rarely practised in either area. Initiation of breast-feeding within 1 hour was more common in the urban area $(82 \%)$ than in the rural area (52\%), $(P=0.001)$. All the infants in both areas were being breast-fed at the time of the study and 98\% were breast-fed on demand. In the rural area $51 \%$ of the mothers gave breast milk as the first feed after delivery, compared to $89 \%$ in the urban area $(P=0.001)$. About $43 \%$ of the rural mothers discarded some of the colostrum, compared to $10 \%$ of the urban mothers $(P=$ 0.001). Water supplementation tended to start very early. In the whole sample, only three infants from the urban area were given gripe water and two glucose water.

The breast-feeding pattern from birth, based on a survival analysis of recall data, is shown in Fig. 2. The mean duration of exclusive breast-feeding was $9 \pm 19$ days in the rural sample and $23 \pm 34$ days in the urban 


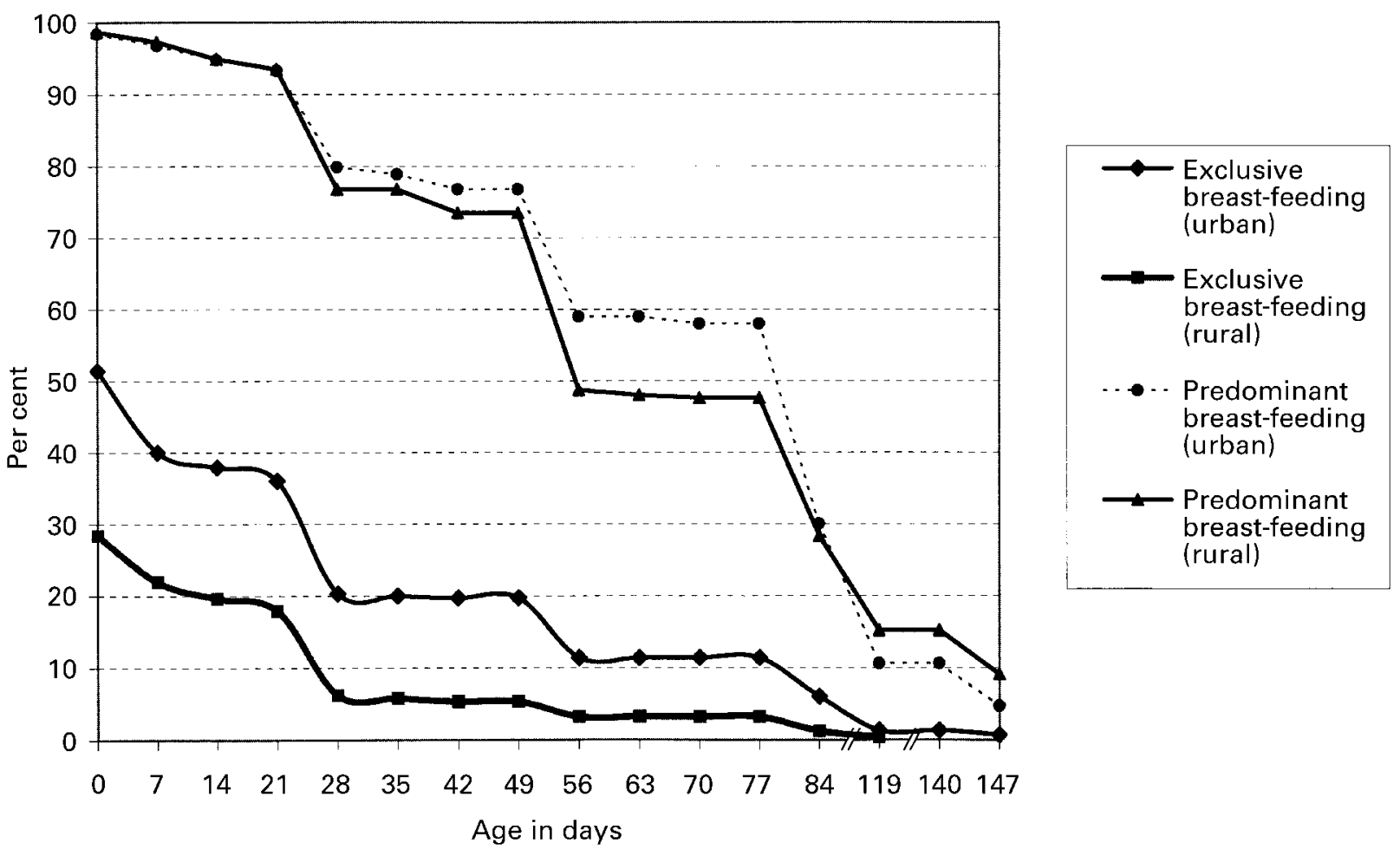

Fig. 2 Infant feeding pattern by age in Morogoro rural and urban districts based on recall data

one $(P=0.001)$. With the introduction of solid foods, the infants shifted from the predominant to the partial breastfeeding category. In the rural sample, this occurred at a median age of 56 days, compared to 77 days in the urban sample $(P=0.001)$.

\section{Breast-feeding duration}

The multiparous mothers in the rural sample had breastfed the previous sibling for a mean duration of $27 \pm 5$ months $(n=224)$, while the corresponding urban mothers had done so for $24 \pm 5$ months $(n=175)(P=$ 0.001). The main reasons stated by both groups for stopping breast-feeding included: child old enough, pregnancy, child refused the breast, infant or maternal illness, and a wish to make the child start eating other foods.

\section{Discussion}

The purpose of the present study was to investigate and compare feeding practices among infants less than 7 months old in a rural and an urban area in Tanzania. The quality of breast-feeding practised was suboptimal in both areas studied. Data are needed for designing appropriate, locally adopted and relevant interventions to improve the observed situation.

Breast-feeding practices are generally better in rural than in urban areas in other African countries ${ }^{13}$. In the present sample, however, breast-feeding practices in the urban areas were better on practically all counts than in the rural areas, except for the duration of any breastfeeding. Haggerty and Rutsten ${ }^{3}$ reported an earlier initiation of breast-feeding in urban areas in 10 out of 17 sub-Saharan countries for which data were available. Otherwise delay in initiation and discarding of colostrum was observed more in rural than in urban $\operatorname{areas}^{23,24,27,30,31}$. Other studies have suggested that prelacteal feeds are given to infants in both rural and urban $\operatorname{areas}^{7,20,27,32}$ except in Sudan, where breast milk was given as the first feed to a higher proportion of infants in the urban areas than in the rural ones ${ }^{8}$. The proportion of infants less than 4 months of age who were fully breastfed in 17 studied countries in sub-Saharan Africa was higher in the rural areas than in the urban areas. The rate of exclusive breast-feeding was too low to be reported separately ${ }^{3}$.

In the present study it was observed that the previous harmful hospital routine of giving newborns glucose seems to have been stopped. Also, the use of gripe water now seems to be rare.

We speculate that the differences in practices between rural and urban areas could at least partly be due to information given at the urban centres following the introduction of the BFHI, which provided in-service training to selected health staff. In other studies factors that have been found to increase exclusive breast-feeding rates have included changes in the knowledge, skills and attitudes of health care staff, accompanied by supportive hospital routines and practices ${ }^{33-35}$.

Although we observed some encouraging signs in early 
infant feeding in this population, the feeding practices we describe are still far from the norms recommended by WHO and the United Nations Children's Fund (UNICEF). Exclusive breast-feeding is rare, a sizeable proportion discards their colostrum, and premature complementation is the norm. Intensified efforts are needed to improve the situation. The BFHI has probably not reached the rural areas, but if it has there was little effect, as initiation of breast-feeding is delayed, a high proportion of the mothers discard colostrum, and water is more often given as the first feed. Since the majority of rural mothers do not deliver at health facilities and contact with the facility may be late or limited, there is a need to strengthen and adopt the BFHI community support aspect so as to make the initiative more relevant to the situation of the majority of rural mothers by developing a 'baby friendly community initiative ${ }^{36,37}$.

We also found that there was a lack of knowledge on key issues regarding breast-feeding management and maintenance in both areas. Introduction to the concept of milk expression and its technique could be useful for feeding low birth weight babies and sick children who otherwise risk being given substitutes. In addition, there is a need to inform the mothers as well as society as a whole about the advantages conferred to the mother and the community by breast-feeding. Such information may help the community to acknowledge the contribution of the mother to the family and nation through breast-feeding and inspire them to create the circumstances necessary for her to able to breast-feed successfully.

Maternal mothers, in addition to health professionals, husbands, village health workers and traditional birth attendants, were found to have had an influential role in child feeding practices. These groups also constitute important facilitators of infant feeding practices and should be given the necessary training, guidance and support ${ }^{36}$.

In summary, the present study revealed substantial ruralurban differences in early infant feeding practices, though in both areas early supplementation is widespread. The better overall breast-feeding performance among urban mothers might be partly attributable to the implementation of the BFHI in urban hospitals and health centres. However, there is a clear need to intensify this initiative in the urban areas, and to energetically introduce it in the rural areas. The situation in the rural areas is of particular concern since exclusive breast-feeding is rare and of short duration. In addition, a high proportion of rural infants are being deprived of the immunological and nutritional benefits of colostrum. Further research is needed to obtain more data to form a basis for tailoring support regarding breast-feeding to both rural and urban mothers.

\section{Acknowledgements}

This study was carried out by the Tanzania Food and Nutrition Centre, Dar es Salaam, Tanzania in collaboration with the Section for International Maternal and Child Health (IMCH), Department of Women's and Children's Health, Uppsala University, Sweden. We express our gratitude to the Swedish International Development Cooperation Agency (Sida) for financial support provided to the Tanzania Food and Nutrition Centre. The additional funding provided by IMCH is highly appreciated. Our sincere appreciation goes to the Morogoro region administration for their cooperation and valuable assistance during the course of the study. We are indebted to the mothers and infants who participated.

\section{References}

1 WHO. Breastfeeding: the Technical Basis and Recommendations for Action. 2nd edn. Geneva: World Health Organization, 1993.

2 WHO. The WHO Global Data Bank. Geneva: World Health Organization, 1996.

3 Haggerty PA, Rutsten SO. Breastfeeding and Complementary Infant Feeding, and the Postpartum Effects of Breastfeeding. Demographic and Health Survey. Comparative Studies No. 30. Calverton, MD: Macro International Inc., 1999.

4 Aarts C, Kylberg E, Hörnell A, Hofvander Y, Gebre-Medhin M, Greiner T. How exclusive is exclusive breastfeeding? A comparison of data since birth with current status data. Int. J. Epidemiol. in press.

5 Omondi LO, Persson LA, Staugård F. Determinants for bottle feeding in Botswana. J. Trop. Pediatr. 1990; 36: 28-33.

6 Shahraban A, Abdulla K, Björksten B, Hovfander Y. Patterns of breast feeding and weaning in the United Arab Emirates. $J$ Trop. Pediatr. 1991; 37: 13-16.

7 Ashraf RN, Jalil F, Khan SR, Karlberg J, Lindbland BS, Hanson LA. Early child health in Lahore, Pakistan: V. Feeding patterns. Acta Paediatr. Suppl. 1993; 390: 47-61.

8 Salih MAM, El Bushra HM, Satti SAR, El Fatil AA. Attitudes and practices of breast feeding in Sudanese urban and rural communities. Trop. Geogr. Med. 1993; 45(4): 171-4.

9 Sen PK. Breastfeeding practices in urban and rural communities of West Bengal using standardized indicators. J. Trop. Pediatr. 1993; 39: 319-20.

10 Perez-Escamilla R. Breastfeeding in Africa and the Latin American and Caribbean region: the potential role of urbanization. Trop. Pediatr. 1994; 40: 137-43.

11 Al-Shehri SO, Farag MK, Baldo MH, Aziz KMS. Overview on breastfeeding patterns in Saudi Arabia. J. Trop. Pediatr. 1995; 41(Suppl. 1): 38-44.

12 Hinde PRA, Mturi AJ. Social and economic factors related to breastfeeding durations in Tanzania. Biosoc. Sci. 1996; 28 $347-54$.

13 Perez-Escamilla R. Update on the breastfeeding situation in Africa. Nutr. Res. 1993; 13: 597-609.

14 Macro International Inc./Ministry of Health/Makerere University. Nutrition and Health Status of Young Children and their Mothers in Uganda. Calverton, MD: Macro International Inc., 1996.

15 Haggerty P, Barclay EG, Dustagheer A, Randrianiriana HA, Rakotonirina S, Razafiarisoa B. Nutrition et sant'e des jeunes enfants et de leur mere a Madagascar (Nutrition and health of young children and their mothers in Madagascar). Calverton, MD: Macro International Inc.,1999.

16 Rutstein S, Tesfazion A, Alemu Z, Hill N. Nutrition and Health Status of Young Children and their Mothers in Eritrea. Calverton, MD: Macro International Inc., 1999.

17 Haggerty P, Pande R, Sanchez A, et al. Nutrition and Health Status of Young Children and their Mothers in Mali. Calverton, MD: Macro International Inc., 1998. 
18 Central Statistical Office. Zimbabwe Demographic and Health Survey. Calverton, MD: Macro International Inc., 1995.

19 Abraham MM, Persson LÅ, Omar MM, Wall S. Breast feeding and dietary habits of children in rural Somalia. Acta Paediatr. 1992; 81: 480-3.

20 Hossain MM, Radwan MN, Araf SA, Habib M, DuPont HL. Pre-lacteal infant feeding practices in rural Egypt. Trop. Pediatr. 1992; 38: 317-22.

21 Marandi A, Afzali HM, Hossain AF. The reasons for early weaning among mothers in Teheran. Bull. World Health Organ. 1993; 71(5): 561-9.

22 Nyagawa DR. Practices on exclusive breastfeeding and associated factors in infants under seven months attending MCH clinic in rural Tanzania. Lishe 1993; 6(0856-0528): 1418.

23 Davies-Adetugbo AA. Social-cultural factors and the promotion of exclusive breastfeeding in rural Yoruba communities of Osun state, Nigeria. Soc. Sci. Med. 1997; 45(1): 113-25.

24 Nath DC, Goswami G. Determinants of breastfeeding patterns in an urban society of India. Hum. Biol. 1997; 69(4): 557-73.

25 Sellen DW. Infant and young child feeding practices among African pastoralists: the Datoga of Tanzania. Biosoc. Sci. 1998; 30: 481-99.

26 Ahmed S, Parveen SD, Islam A. Infant feeding practices in rural Bangladesh: policy implications. J. Trop. Pediatr. 1999; 45: 37-41.

27 Okollo SN, Adewunmi CO, Okonji MC. Current breastfeeding knowledge, attitude, and practices of mothers in five rural communities in the Savannah region of Nigeria. J. Trop. Pediatr. 1999; 45: 323-6.

28 Bureau of Statistics/Macro International Inc. Tanzania Demographic and Health Survey. Calverton, MD: Bureau of Statistics and Macro International Inc., 1996.

29 Bureau of Statistics. Population Census. Dar es Salaam: Bureau of Statistics, 1988.

30 Kimati VP. Breastfeeding in rural and urban areas in Tanzania. J. Trop. Pediatr. 1983; 29: 119-23.

31 Morse JM, Jehle C, Gamble D. Initiation breastfeeding: a world survey of timing of postpartum breastfeeding. Int. J. Nurs. Stud. 1990; 27: 303-13.

32 Cosminsky S, Mhloyi M, Ewbank D. Child feeding practices in a rural area of Zimbabwe. Soc. Sci. Med. 1993; 36(7): 93747.

33 Prasad B, Costello AM de L. Impact and sustainability of a 'baby friendly' health education intervention at a district hospital in Bihar, India. BMJ 1995; 310: 621-3.

34 Davies-Adetugbo AA, Fabiyi AK, Ojoofeitimi EO, Adetugbo $\mathrm{K}$. Breastfeeding training improves health worker performance in rural Nigeria. East Afr. Med. J. 1997; 74(8): 510-13.

35 Valdes V, Schooley J. The role of education in breastfeeding success. Food Nutr. Bull. 1996; 17(4): 431-7.

36 Armstrong HC. Breastfeeding as the foundation care. Food Nutr. Bull. 1995; 16(4): 299-312.

37 Semega-Janneh IJ. Breastfeeding: from biology to policy. In: United Nations Administrative Committee on Coordination Subcommittee on Nutrition Challenges for the 21st century: A Gender Perspective on Nutrition through the Life Cycle. Geneva: ACC/SCN, 1998: 83-96. 